\title{
THE ANTIMICROBIAL PROPERTIES OF THE VARIOUS EXTRACTS DERIVED FROM THE PSEUDOBULBS OF COELOGYNE SPECIOSA (BLUME) LINDL. (ORCHIDACEAE) AGAINST STAPHYLOCOCCUS AUREUS
}

\author{
Buyun Lyudmyla**, Tkachenko Halyna ${ }^{2}$, Osadowski Zbigniew ${ }^{2}$, \\ Kovalska Lyudmyla ${ }^{1}$, Gyrenko Oleksandr ${ }^{1}$ \\ ${ }^{1}$ M.M. Gryshko National Botanical Garden, National Academy of Science of Ukraine, Kyiv, Ukraine \\ ${ }^{2}$ Institute of Biology and Environmental Protection, Pomeranian University in Słupsk, Poland \\ Received 25. 6. 2017 \\ Revised 29.6. 2017 \\ Published 24. 11. 2017
}

The present study was conducted to investigate in vitro antimicrobial activity of various extracts obtained from pseudobulbs of an epiphytic orchid Coelogyne speciosa against Staphylococcus aureus strain (ATCC 25923), a clinically important microorganism responsible for many infections. The pseudobulbs of Coelogyne speciosa plants, cultivated under glasshouse conditions, were sampled at M.M. Gryshko National Botanical Garden (Kyiv, Ukraine). Antibacterial activities of the extract obtained from pseudobulbs of Coelogyne speciosa in various solvent systems were assessed. Consequently, five kinds of solvents were used to extract the active ingredients from the pseudobulbs of Coelogyne speciosa. The testing of antibacterial activity of the plant extracts was carried out in vitro by Kirby-Bauer disc diffusion technique. The results revealed that ethanolic extracts from pseudobulbs of Coelogyne speciosa exhibited strong activity against Staphylococcus aureus (inhibition zone diameter was $19 \mathrm{~mm}$ ), while methanol, ethyl acetate, hexane, and dichloromethane extracts had no antibacterial activities. Therefore, the research showed that ethanolic extracts obtained from pseudobulbs of Coelogyne speciosa possess antibacterial potency against $S$. aureus and may be used as natural antiseptics and antimicrobial agents in medicine and veterinary practice. The antimicrobial effect exhibited by Coelogyne speciosa extracts is in agreement with previous data on antimicrobial effects documented for numerous orchid species. Given the medicinal importance of the tested microorganisms, the findings of this research are considered to be very promising in the perspective of new drug development from plant sources. Nevertheless, more research should be carried out to evaluate accurately the roles of particular compounds, isolated from pseudobulb of orchid screened, responsible for the antimicrobial activity.

Keywords: orchids; Coelogyne speciosa; pseudobulb; antimicrobial activity; Kirby-Bauer disc diffusion technique

\section{Introduction}

Over $50 \%$ of all modern drugs are of natural product origin and they play an important role in drug development programs for the pharmaceutical industry (Baker et al., 1995). Moreover, it is apparent that the significance of plant derived medicines has been increasing all over the world. Since Pérez Gutiérrez (2010) highlighted the importance of orchid species as a source of active compounds, interest in orchid properties has been growing. During last few decades many orchid species were

\footnotetext{
*Corresponding author: Lyudmyla Buyun, M.M. Gryshko National Botanical Garden, National Academy
} of Science of Ukraine, Kyiv, Ukraine, $₫$ buyun@nbg.kiev.ua 
screened and a wide range of chemical compounds from medicinal orchids has been identified (Subedi, 2011).

Pseudobulbs are most commonly used parts of orchid plants to cure various disorders, followed by leaves, roots, tubers/rhizomes, and flowers. Major local uses include aphrodisiacs, energizers, and treatments of skin burns, fractured or dislocated bones (both of humans and cattle), headaches, fever, and wounds. Other uses include insect repellent, blood purifier, skin fungi, an antidote against snake bites and scorpion stings, inducement of abortions and recovery from child birth. Moreover, many species of Orchidaceae family also possess antimicrobial activity (Khan and Omoloso, 2004). Orchids are mainly used as paste, powder or juice, solely or mixed with milk, honey or wheat flour. Orchid extracts are either consumed orally or applied externally. Fresh orchid flowers are used to induce vomiting by exposure to a dominant foul smell. Local communities in India and Nepal also commonly eat freshly cut plant of Coelogyne species in the forest when they feel thirsty (Subedi, 2011).

Phytochemical studies in the genus Coelogyne revealed that these plants have a wide array of secondary compounds resulting in profound biological activity, antimicrobial, in particular (Pant, 2013; Sahaya Shibu et al., 2013).

Therefore, the aim of this study was to evaluate the antimicrobial activity of the crude extracts obtained from pseudobulbs of Coelogyne speciosa prepared in different solvent systems against Staphylococcus aureus, a clinically important microorganism responsible for many infections, to support the use of these extracts as novel natural products for compounded bacterial-treatment modalities. Coelogyne speciosa (Blume) Lindl. belongs to the section Speciosae, distributed from mainland Southeast Asia (Thailand), all over Malesia to the islands in the Pacific Ocean (Gravendeel, 2000).

\section{Materials and methodology}

\section{Collection of plant material}

The pseudobulbs of Coelogyne speciosa plants, cultivated under glasshouse conditions, were sampled at M.M. Gryshko National Botanical Garden (NBG), National Academy of Science of Ukraine (Figure 1). Since 1999, the whole collection of tropical and subtropical plants (including orchids) has the status of a National Heritage Collection of Ukraine. Besides that, NBG collection of tropical orchids was registered at the Administrative Organ of CITES in Ukraine (Ministry of Environmental Protection, registration No. 6939/19/1-10 of 23 June 2004).

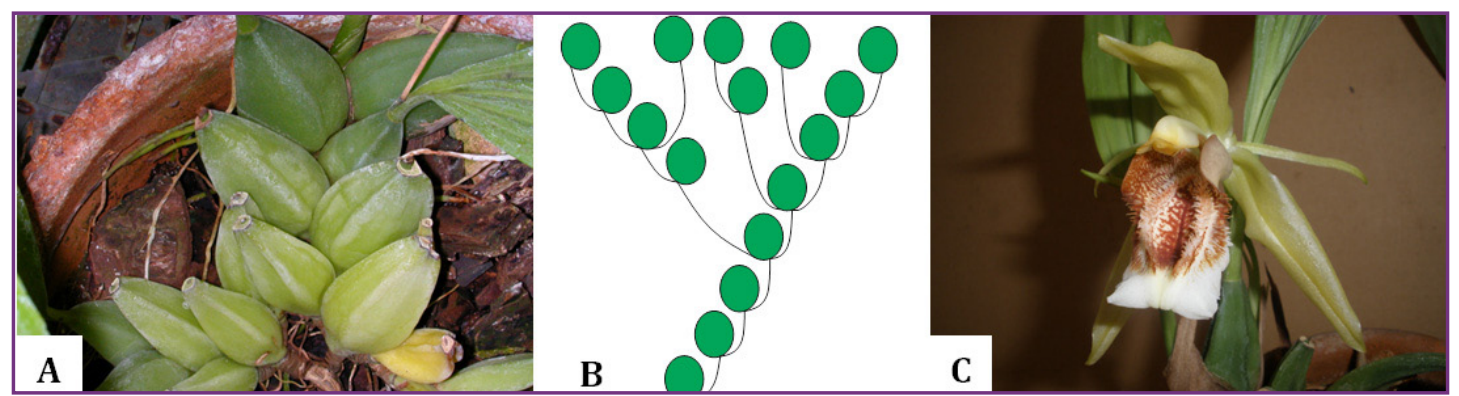

Figure 1 Coelogyne speciosa (Blume) Lindl. plant cultivated at M.M. Gryshko National Botanical Garden glasshouses

A - an arrangement of pseudobulbs on the rhizome; B - branching pattern of shoot system; C - general view of flower 
Pseudobulbs are ovoid and clustered on rhizome, obtusely 4-angled when young (Figure 1A). Synanthous inflorescences, characteristic feature for Coelogyne speciosa, are predominant in the section Speciosae: the inflorescence-bearing shoot has an immature pseudobulb hidden in the basal scales and the young leaf or leaves on top of this pseudobulb starts swelling and leaf or leaves fully develop (Gravendeel and de Vogel, 1999).

Laboratory work was carried out in the Institute of Biology and Environmental Protection, Pomeranian University in Słupsk (Poland).

\section{Preparation of plant extracts}

Freshly collected pseudobulbs were washed, weighted, crushed, and homogenized in $96 \%$ ethanol, methanol, ethyl acetate, hexane, and dichloromethane (in proportion $1: 19$ ) at room temperature. Consequently five kinds of solvent systems were used to extract the active ingredients from pseudobulbs of Coelogyne speciosa.

Bacterial Growth Inhibition Test of Plant Extracts by the Disk Diffusion Method

Antimicrobial activity was determined using the agar disk diffusion assay (Bauer et al., 1966). Cultures of Staphylococcus aureus (ATCC 25923) were suspended in a sterile solution of $0.9 \%$ normal saline and the turbidity adjusted equivalent to that of a $0.5 \mathrm{McFarland}$ standard. The culture was inoculated onto Mueller-Hinton $(\mathrm{MH})$ agar plates. Sterile filter paper discs impregnated with extract dilutions were applied over each of the culture plates. Isolates of bacteria were then incubated at $37{ }^{\circ} \mathrm{C}$ for $24 \mathrm{~h}$. The plates were then observed for the zone of inhibition produced by the antimicrobial activity of Coelogyne speciosa. A negative control disc impregnated with sterile ethanol, methanol, ethyl acetate, hexane, and dichloromethane was used in each experiment. The antimicrobial activities of the extracts tested were evaluated at the end of the inoculated period by measuring the inhibition zone diameter around each paper disc in millimeters. The plates were observed and photographs were taken. For each extract six replicate trials were conducted. Zone diameters were determined and averaged. All statistical calculations were performed on separate data from each bacterial strain. The following zone diameter criteria were used to assign susceptibility or resistance of bacteria to the phytochemicals tested: Susceptible $(S) \geq 15 \mathrm{~mm}$, Intermediate $(I)=11-14 \mathrm{~mm}$, and Resistant $(R) \leq 10 \mathrm{~mm}$ (Okoth et al., 2013).

\section{Results and discussion}

In the present study, the effect of extracts obtained from pseudobulbs of Coelogyne speciosa prepared in various solvents on the growth of S. aureus was investigated in vitro. The results revealed that ethanolic extracts from pseudobulbs of Coelogyne speciosa exhibited strong activity against Staphylococcus aureus (inhibition zone diameter was $19 \mathrm{~mm}$ ), while the methanolic extract from pseudobulbs revealed mild activity $(8 \mathrm{~mm}$ ) (Figure 2 and 3). Moreover, it has been observed that ethyl acetate, hexane and dichloromethane extracts obtained from pseudobulbs of Coelogyne speciosa revealed no antibacterial activity against Staphylococcus aureus.

Detailed data regarding the zones of inhibition by the various plant extracts were recorded and presented in Figure 2.

The results obtained from the present study are consistent with earlier reports, which found that other species of Coelogyne have noticeable phytochemical, antimicrobial, antioxidant and anticancer activity (Sahaya Shibu et al., 2013). In our previous study (Buyun et al., 2016a-f, Góralczyk et al., 2016, 
Tkachenko et al., 2015, 2016), we have reinforced the assumption that Coelogyne species could be potential antibacterial or antifungal agents resource.

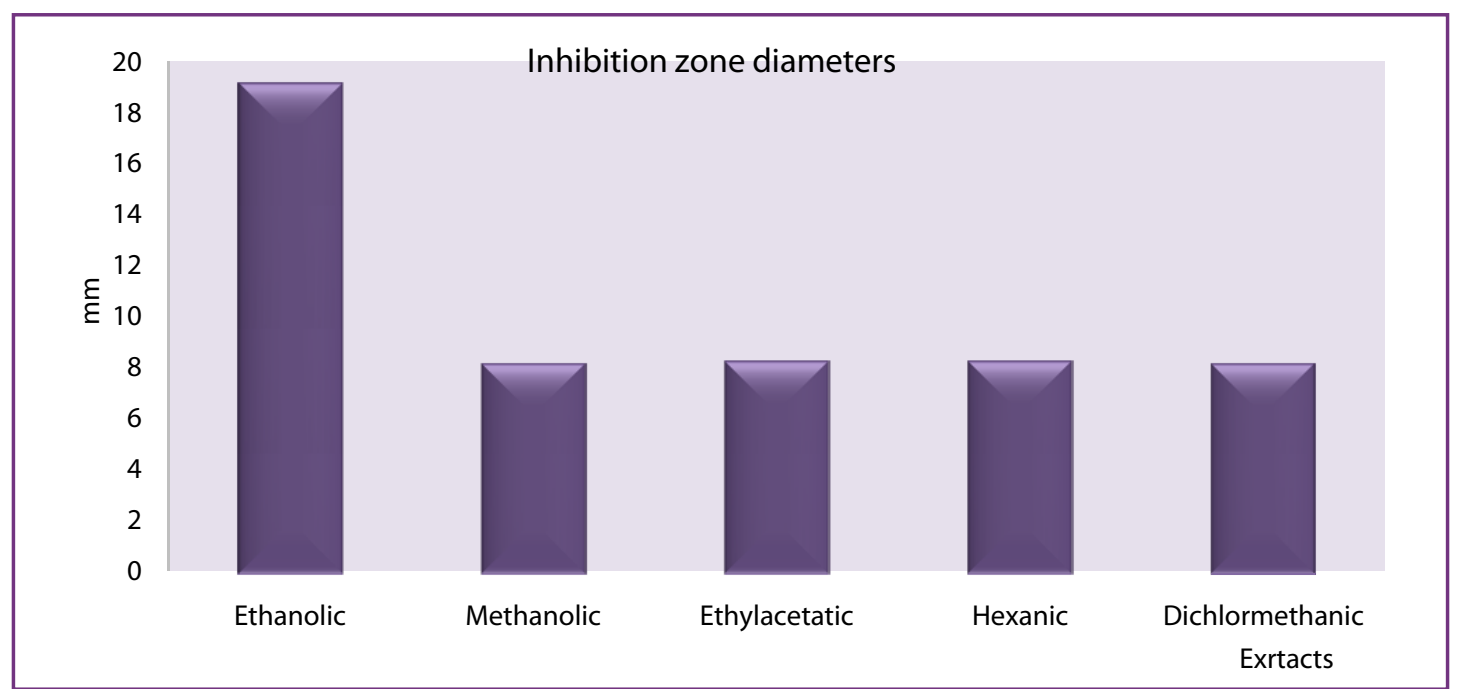

Figure 2 Antimicrobial activity of various extracts obtained from pseudobulbs of Coelogyne speciosa (Blume) Lindl. against Staphylococcus aureus measured as inhibition zone diameter

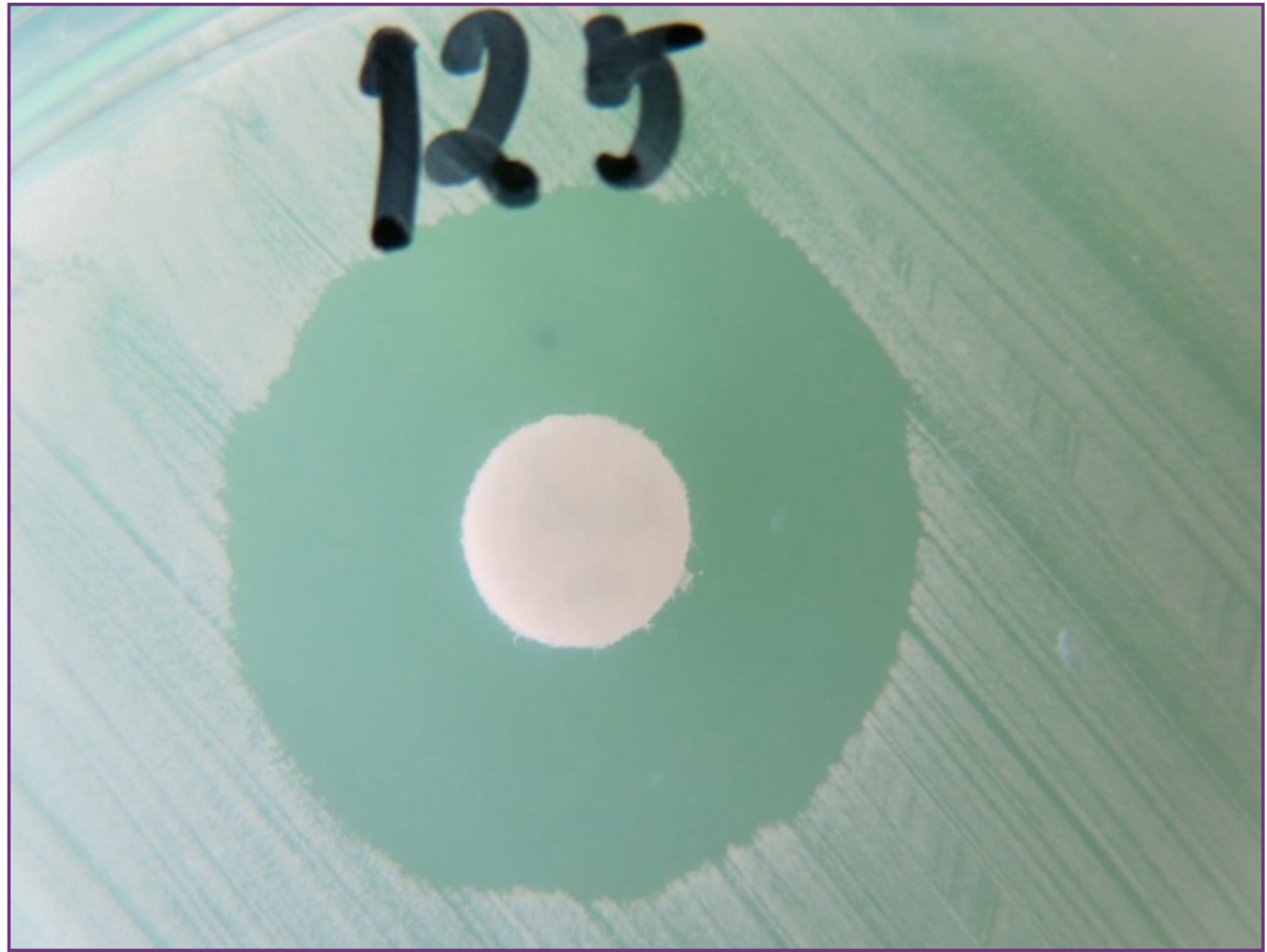

Figure 3 Antibacterial spectrum of ethanolic extract obtained from pseudobulbs of Coelogyne speciosa (Blume) Lindl. against Staphylococcus aureus measured as inhibition zone diameter 
The orchid extracts from various species of Coelogyne genus displayed varied antimicrobial and antifungal potency. We have determined antifungal potential of eleven species of orchids namely Coelogyne viscosa Lindl., Coelogyne cristata Lindl., Coelogyne lawrenceana Rolfe, Coelogyne pandurata Lindl., Coelogyne assamica Linden \& Rchb.f., Coelogyne fimbriata Lindl., Coelogyne ovalis Lindl., Coelogyne asperata Lindl., Coelogyne speciosa (Blume) Lindl., Coelogyne tomentosa Lindl. and Coelogyne brachyptera Rchb.f. against Candida albicans (Tkachenko et al., 2015). Ethanolic orchid leaf extracts resulted in considerable suppression of S. aureus growth (Tkachenko et al., 2016). Among orchids selected, marked antimicrobial efficacy was observed for Coelogyne cristata (mean diameter of growth of inhibition zones was $27.5 \mathrm{~mm}$ ), Coelogyne tomentosa (26 mm), Coelogyne lawrenceana (26 mm), Coelogyne brachyptera $(26 \mathrm{~mm})$, Coelogyne viscosa $(25.5 \mathrm{~mm})$, Coelogyne pandurata $(24.5 \mathrm{~mm})$, and Coelogyne fimbriata $(24 \mathrm{~mm})$. Thus, our results showed that different extracts of epiphytic orchids from Coelogyne genus have potent antimicrobial properties against Staphylococcus aureus (Tkachenko et al., 2016).

Previously, we have investigated the antibacterial effects of ethanolic extract of Coelogyne brachyptera leaves against specific Gram-positive (Staphylococcus aureus ATCC 25923 and methicillin-resistant Staphylococcus aureus locally isolated) and Gram-negative bacteria (Pseudomonas aeruginosa ATCC 27853 and Escherichia coli ATCC 25922) and fungal strain (Candida albicans) (Buyun et al., 2016e). Our results showed that the ethanolic extract of Coelogyne brachyptera leaves showed strong activity against the Gram-positive bacterial strains $(20 \mathrm{~mm}$ diameter of inhibition zone for Staphylococcus aureus and $26 \mathrm{~mm}$ for meticillin-resistant Staphylococcus aureus), and moderate activity against the Gram-negative bacteria (14 mm for Escherichia coli and $11 \mathrm{~mm}$ for Pseudomonas aeruginosa). Extract of Coelogyne brachyptera has displayed strong inhibitory activity against test fungus Coelogyne albicans (mean diameter of inhibition zone was $17.2 \mathrm{~mm}$ ) (Buyun et al., 2016e). The ethanolic extract of Coelogyne ovalis leaves showed strong activity against Staphylococcus aureus (27 mm of inhibition zone diameter), while an ethanolic extract from pseudobulbs revealed less activity (22 mm). Methanolic and ethyl acetate extracts obtained from Coelogyne ovalis leaves also showed appreciable antimicrobial activity (32 $\mathrm{mm}$ and $35 \mathrm{~mm}$, respectively), whereas those extracts from pseudobulbs revealed no antibacterial activity against Staphylococcus aureus (Buyun et al., 2016a).

Also, the results obtained from the present research showed the antimicrobial potential of Coelogyne speciosa extracts against Staphylococcus aureus. So, these plants extracts can be used as antiseptics and antimicrobial agents in medicine and veterinary. The antibacterial activity in Coelogyne may be due to a presence of alkaloids, bibenzyl derivatives, flavonoids, phenanthrenes, and terpenoids.

Clinical studies confirmed diuretic, anti-rheumatic, anti-inflammatory, anti-carciogenic, antimicrobial, anticonvulsive, relaxation, neuro-protective and antivirus activities (Pérez Gutiérrez, 2010).

Presence of these phytochemicals provides antimicrobial, antitumor, anti-inflammatory, antiviral activities, etc. A number of members of the orchid family are used as potent inhibitor against bacteria and also proved to be a potent antimicrobial agent. The methanolic extract from different parts of orchids has shown antimicrobial activity. A broad spectrum antibacterial activity (24 bacteria and protozoan) was exhibited by Galeola foliata leaves and stem bark extracted with petrol, dichloromethane, ethyl acetate, butanol, and methanol. A very good level of activity was demonstrated by the dichloromethane and ethyl acetate fractions (Khan and Omoloso, 2004). 


\section{Conclusion}

The examined ethanolic extracts obtained from pseudobulbs of Coelogyne speciosa showed different antibacterial activities against Staphylococcus aureus, while methanol, ethyl acetate, hexane, and dichloromethane extracts had no antibacterial activities. The observed activity may contribute to the reasons why orchids are used for infectious and inflammatory conditions in ethnomedicine. The research showed that ethanolic extracts of Coelogyne speciosa possess antibacterial potency against Staphylococcus aureus. These findings led the authors to suggest that these extracts may be used as a natural antiseptics and antimicrobial agents in medicine and veterinary practice. Taking into account the medicinal importance of the tested microorganism, the data of this research are considered to be very promising in the perspective of new drug development from plant sources. Nevertheless, despite the promising results, more research should be carried out to further evaluate the roles of particular compounds, isolated from all parts of orchid plants, attributable to antimicrobial activity.

\section{References}

Baker, J.T., Borris, R.P., Carte, B., Cordell, G.A., Soejarto, D.D. 1995. Natural product drug discovery and development: New perspective on international collaboration. J. Natl. Prod., vol. 58, p. 1325-1357. Available at: https://www.ncbi.nlm.nih.gov/pubmed/7494142

Bauer, A.W., Kirbi, W.M., Sherris, J.C., Turk, M. 1966. Antibiotic susceptibility testing by a standardized single disk method. Am. J. Clin. Pathol., vol. 45, no. 4, p. 493-496.

Buyun, L., Tkachenko, H., Kovalska, L., Osadowski, Z. 2016a. Preliminary screening of Coelogyne ovalis Lindl. (Orchidaceae) for antimicrobial activity against Staphylococcus aureus. Dni laboratornoy meditsiny. Grodno: GrGMU, p. 10. ISBN 978-985-558-668-6.

Buyun, L., Tkachenko, H., Osadowski, Z. 2016b. Antimicrobial activities of the various extracts obtained from leaves and pseudobulbs of Coelogyne tomentosa Lindl. (Orchidaceae). Ekolohiya - filosofiya isnuvannya lyudstva, Kyiv, p. 10-12.

Buyun, L., Tkachenko, H., Osadowski, Z., Kovalska, L. 2016c. Antimicrobial activities of the various extracts obtained from leaves and pseudobulbs of Coelogyne huettneriana Rchb.f. (Orchidaceae). Ontohenez stan, problemy ta perspektyvy vyvchennya roslyn $v$ kulturnykh ta pryrodnykh tsenozakh, Kherson : RVTs «Kolos», p. 8-11. Available at: https://www.researchgate.net/publication/304539606

Buyun, L., Tkachenko, H., Osadowsky, Z., Kovalska, L., Gyrenko, O. 2016d. Antimicrobial activity screening of extracts from leaves and pseudobulbs of Coelogyne cristata Lindl. (Orchidaceae). Agrobiodiversity for improving nutrition, health, and life quality, Nitra, p. 40-44. ISBN 978-80-552-1586-0.

Buyun, L., Tkachenko, H., Osadowski, Z. 2016e. Antibacterial and antifungal activity of the ethanolic extract from Coelogyne brachyptera Rchb. f. leaves (Orchidaceae). Sustainable technologies and the legal economic aspects of agricultural production, Kyiv, p. 133-135.

Buyun, L., Tkachenko, H., Osadowski, Z., Góralczyk, A., Kovalska, L., Gyrenko, O. 2016f. Antimicrobial screening of the various extracts derived from the leaves and pseudobulbs of Coelogyne speciosa (Blume) Lindl. (Orchidaceae). Słupskie Prace Biologiczne, vol. 13, p, 37-54. ISSN 1734-0926.

Góralczyk, A., Tkachenko, H., Buyun, L., Osadowski, Z. 2016. The antimicrobial potential of ethanolic extract of Coelogyne cristata Lindl. (Orchidaceae) leaves. Youth and Progress of Biology, Lviv, p. 259-260.

Gravendeel, B. 2000. Reorganising the orchid genus Coelogyne: a phylogenetic classification based on morphology and molecules. Leiden : Leiden University, 208 p.

Gravendeel, B., de Vogel, E.F. 1999. Revision of Coelogyne section Speciosae (Orchidaceae). Blumea, vol. 44, p. 253-320. Available at: http://www.repository.naturalis.nl/record/524978

Khan, M.R., Omoloso, A.D. 2004. Antibacterial activity of Galeola foliata. Fitoterapia, vol. 75, no. 5, p. 494-496. 
Okoth, D.A., Chenia, H.Y., Koorbanally, N.A. 2013. Antibacterial and antioxidant activities of flavonoids from Lannea alata (Engl.) Engl. (Anacardiaceae). Phytochem. Lett., vol. 6, p. 476-481. Available at: http:// dx.doi.org/10.1016/j.phytol.2013.06.003

Pant, B. 2013. Medicinal orchids and their uses: Tissue culture a potential alternative for conservation. Afr. J. Plant Sci., vol. 7, no. 10, p. 448-467. DOI: 10.5897/AJPS2013.1031.

Pérez Gutiérrez, R.M. 2010. Orchids: A review of uses in traditional medicine, its phytochemistry and pharmacology. Journal of Medicinal Plants Research, vol. 4, no. 8, p. 592-638. DOI: 10.5897/JMPR10.012.

Sahaya Shibu, B., Chitra Devi, B., Sarmad Moin, L., Servin Wesley, P. 2013. Evaluation of bioactive potential of Coelogyne nervosa A. Rich. - an endemic medicinal orchid of western Ghats, India. Asian J. Pharm. Clin. Res., vol. 6, no. 1, p. 114-118. ISSN 0974-2441.

Subedi, A. 2011. New species, pollinator interactions and pharmaceutical potential of Himalayan orchids: dissertation thesis, Leiden : Leiden University. Available at: http://hdl.handle.net/1887/17943

Tkachenko, G.M., Truchan, M.A., Buyun, L.I., Son, H.N., Chiong, M. 2016. Antibakterialnaya effektivnost nekotorykh vidov orkhidey roda Coelogyne Lindl. v otnoshenii zolotistogo stafilokokka. Materialy XI Mezhdunarodnoy (XX Vserossiyskoy) Pirogovskoy nauchnoy meditsinskoy konferentsii studentov i molodykh uchenykh, Moskva, p. 632-633.

Tkachenko, G.M., Truchan, M.A., Buyun, L., Kovalska, L., Gyrenko, A. 2015. Antifungal efficacy of some orchids from Coelogyne Lindl. genus against Candida albicans. Intehrovanyi zakhyst ta karantyn roslyn. Perspektyvy rozvytku v XXI stolitti, Kyiv, p. 178-181. DOI: 10.13140/RG.2.1.3305.8648. 